\title{
Odour Impact Assessment by Means of Dispersion Modeling, Dynamic Olfactometry and Mobile Electronic Nose around Agadir Fishing Port in Morocco
}

\author{
Ahmed Chirmata*, Ihya Ait Ichou \\ AQUAMAR Laboratory, Photocatalysis and Environment Team, Department of Chemistry, Faculty of Sciences, Ibn Zohr University, \\ Agadir, Morocco \\ Email: ${ }^{*}$ chirmata@yahoo.fr
}

How to cite this paper: Chirmata, A. and Ichou, I.A. (2016) Odour Impact Assessment by Means of Dispersion Modeling, Dynamic Olfactometry and Mobile Electronic Nose around Agadir Fishing Port in Morocco. Journal of Environmental Protection, 7, 1745-1764.

http://dx.doi.org/10.4236/jep.2016.712141

Received: September 1, 2016

Accepted: November 11, 2016

Published: November 14, 2016

Copyright $\odot 2016$ by authors and Scientific Research Publishing Inc. This work is licensed under the Creative Commons Attribution International License (CC BY 4.0).

http://creativecommons.org/licenses/by/4.0/ (c) (i) Open Access

\section{Abstract}

Odorous emissions emitted from various sources including industrial and commercial activities have particular concerns about human health. These malodors emissions are an environmental concern that affects health status and social life of the neighbors. That requires the local authority to set up a management strategy to control this nuisance. The evaluation of odour emissions from fishing port is complex because these emissions depend on several factors such as multiple sources of odor emissions, meteorological conditions, topography and others. That imposes the use of complementary approaches to monitor odours. In this paper, the case of Agadir fishing port is studied, which is adjacent to the tourist area and residential neighborhoods and which hosts a number of points that can generate odors. To assess this odour impact, three methods are used such as dynamic olfactometry, dispersion modeling and mobile electronic nose (e-nose). The use of these three methods in a complementary manner to assess odour impacts around a fishing port allowed both the quantification of the emissions using dynamic olfactometry and the evaluation of their impact on the study area with model dispersion. The results enabled also to identify the most affected areas of the city by odor emissions and to recognize the meteorological parameters maximizing odor impact. The other goal of this work is to compare the results of the odour dispersion modeling and e-nose measurements for one year in terms of frequency of overtaking the set alert thresholds over the same period. Comparison highlights the strengths and weaknesses of both approaches. Modeling can be used predicatively but it does not take into account fugitive emissions reliably in the absence of data on these emissions, modeling based on the hourly average misjudges the odor peaks, while e-nose made it possible to obtain 
validated data and provides accurate, affordable and real-time odour measurement capability tacking in to account the role of human perception without being able to characterize the extent of the odor nuisance caused by each source. We conclude that these three valuation methods provide complementary information about odor nuisance and reasonable estimates of odors.

\section{Keywords}

Electronic Nose, Odor Dispersion Modeling, Dynamic Olfactometry, Odor Impact Assessment, AERMOD

\section{Introduction}

Odor emissions induced by various sources including industrial and commercial activities are an environmental problem that can affect moods and have psychological and physiological impacts on people's daily lives [1], odour nuisance issues are particularly worrying when more industrial activities exist near residential areas [2]. Unpleasant odors are major cause of public complaints concerning air quality to the competent authorities, thus odours are now recognized as atmospheric pollutants and are subject to control and regulation in many countries [3]. Reactions to odors can result in a large variety of effects, generally the impact of an odour results from a combination of interacting factors, collectively known as FIDOL; namely, frequency (F), intensity (I), duration (D), offensiveness (O), and location (L) [4]. These characteristics of an odour are taken in to account when assessing its offensiveness.

The odour impact assessment is based on four steps: the quantification of the emissions, the evaluation of odor impact using dispersion models which calculating time series of one-hour mean values, short-time peak concentrations to mimic odour sensation of the human nose, which are derived from these one-hour mean values, and the odour impact criteria, defined by the odour concentration threshold and its exceedance probability which enable to assess the environmental impact of the odour source [5].

The assessment of odor pollution is still regarded as a difficult task, because olfactory nuisance can be caused by many different chemical compounds. The development of standardized assessment approaches to odor pollution and proper international regulatory tools are urgently needed. In particular, comparisons of the methodologies commonly used nowadays to assess odor impacts on air quality are required [6].

In this paper, we investigate the case of Agadir fishing port, located adjacent to downtown and the weather makes them the major source of odor pollution that affects the tourist area and the origin of the various complaints from neighbors and even in the whole tourist area. The management of this odor pollution is a major concern for both the local authorities who must control the nuisance generated and for residents who claim the respect and well-being.

The measurements of key offensive odorants in a fishery industrial complex, found 
in the literature, show that the ammonia $\left(\mathrm{NH}_{3}\right)$ was significantly higher than those of any other odorant, the mean concentrations of hydrogen sulfide $\left(\mathrm{H}_{2} \mathrm{~S}\right)$, methyl mercap$\tan \left(\mathrm{CH}_{3} \mathrm{SH}\right)$ and trimethylamine $\left(\left(\mathrm{CH}_{3}\right)_{3} \mathrm{~N}\right)$ in the major fishery facilities greatly exceeded the odorant emission guideline regulated at the industrial area. Such excess of concentrations will be a health risk for the people who work or live here. The methyl mercaptan and the trimethylamine are considered to be the major odorants at the major fishery facilities and the border area in the fishery industrial area [7].

In this study, the assessment of odour impacts around a fishing port is conduct meaning the identification of the major odour sources, the quantification of the emissions using dynamic olfactometry and the evaluation of odor impact on the study area with a model and then the results of the odour dispersion modeling are validated using the mobile electronic nose (e-nose).

The use of these three methods in a complementary manner allowed identifying specific parameters generating olfactory nuisances in the residential neighbourhoods and spying out meteorological conditions under which olfactory nuisances are to be expected and to identify the most affected areas of the city by odor emissions, in this paper, also the ambient odor levels measured using e-nose are compared to those predicted by AERMOD.

\section{Materials and Methods}

\subsection{Site Description}

The Agadir fishing port is the largest sardine port in the world, located in the Atlantic coast of Morocco, at the Northwest of downtown with the beach and many hotels and restaurants, the industrial zone of Anza is the nearest in the north, it is surrounded in north east by the mountain range.

Through its activities, the Agadir fishing port is a source of odor emissions, potentially generating odors comparable in terms of odor character to odor emitted from fishery facilities.

The fishing port has many outdoor storage areas of fresh fish. More specifically, there is a loading zone and unloading fish dedicated to fish meal production plants. This area is sometimes hindered by a large number of fish directly spilled on the floor (over 200 $\mathrm{m}^{2}$ ). This area is suspected to be a source of odor nuisance impact on the identified areas. Even if the gas flow rate is relatively low, the odor concentration and extent of the source makes it an important source of odor nuisance. Figure 1 shows the geographical map of the study area comprising the emission region (the fishing port of Agadir) and the impact zones (industrial zone of Anza, tourist area and city center) and the prevailing wind direction.

For the topography, the study area is at an average altitude of 40 meters above the sea level and the ground has low elevation changes which are taken into account by the model.

The study area was established to a size of $15 \mathrm{~km}$ by $15 \mathrm{~km}$ to reach the main areas of the city bordering the odor nuisance sources identified. 


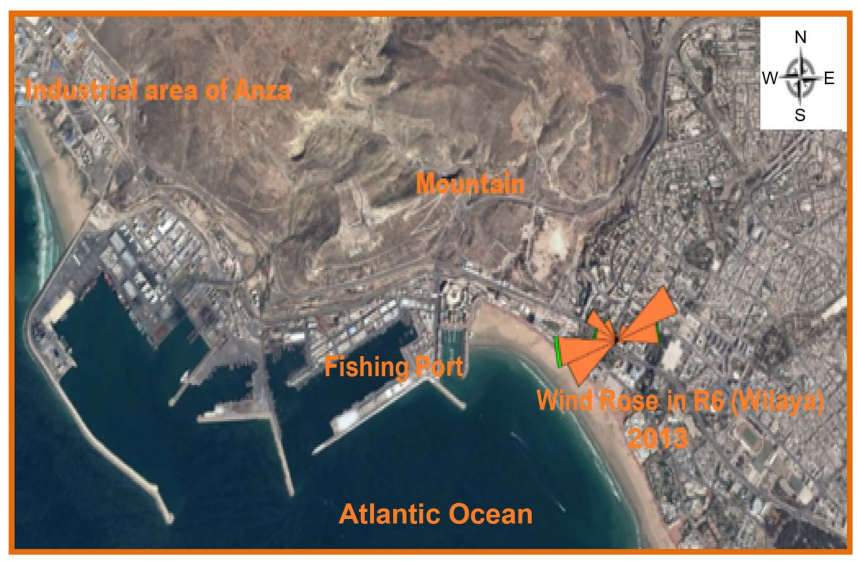

Figure 1. The study area and localization of odor sources (fishing port).

\subsection{Measurements and Methods}

The case study concerns the assessment of the olfactory nuisance caused by different sources from fishing port, identified as major sources of odor nuisance on the seaside area of Agadir, in addition to fishing facilities located in the Anza area in the north of Agadir for which production and consequently the odor generation becomes important only in the afternoon until midnight.

The measures are taken in the morning when the fishing port can be considered as the main source of odor in the area. The odor concentrations released at the emission sources are measured and then it's evaluated at the receptors to establish a link between emissions and impacts.

In this study, two main techniques are used to measure odor concentration in ambient air. The first technique is represented by analytical methods which the most particle one being the e-nose. As a human olfaction system, the e-nose is a highly complex instrument; it has a capability of recognizing and discriminating between a variety of different gases and odors using just a small number of sensors.

The sensor array and the nature of each individual sensor are the most important features of any e-nose. The volatile compounds interact with the sensor surfaces and cause a change in certain chemical and physical properties of the latter. These variations are then converted to an electronic signal which is sent to the data processing system [8].

Research has led to the e-nose applications in various different fields, thus e-nose has been applied to many real applications, such as quality control of food products, safety and security, environmental monitoring, medical diagnosis and soon.

For environmental monitoring, the e-nose is able to monitor gas emissions in real time in the field and to link them to the odour concentration expressed in odour units [9].

In this study, the e-nose used is from Odotech which is equipped with metal-oxide semiconductors (MOS) sensors that are slightly sensitive to different classes of chemical compounds, these sensors were specifically set up and trained with samples collected at 
the monitored major sources of odor nuisance. The e-nose does not recognize the individual odor-generating compounds, but rather provides an olfactory signature (fingerprint) of the analyzed air [10].

It's noted that an earlier work was carried out to validate the use of e-nose the same mark for monitoring odors in the same area using the sensorial techniques, based on the detection of odors by means of the human nose, for this case study, 6 panel members made observations every 4 seconds (response time of e-nose) for duration up to ten minutes at four alert point of the continuous electronic nose odor monitoring system (Odowatch from Odotech), this inspection grid has been defined taken in account the citizen complaints about malodours and information on the prevailing wind [11], the odour measurements by field inspection was carried out in accordance with the guideline VDI 3940 prepared by the Association of German Engineers, through this work, number of threshold violations are approximately the same for tow techniques.

It's noted that the Community survey is the low cost methodology compared to others methods to asses odour impacts from facilities in urban areas taking into account past experiences, seasonal effects and the role of human perception through social participation, but it is difficult to insure impartial judgement in order to avoid errors in the responses [12].

The second method is the use of dispersion model (AERMOD), which is one among analytical models preferred by regulatory agencies to evaluate odor impacts, due to their low cost, easy application and fast operation. It based on site topography, meteorological data and odor emission rates measured with the dynamic dilution olfactometry technique according to standard procedure described by the EN 13725 (2003).

\subsection{Model Used}

Odor dispersion modeling has been used as a reliable and cost-effective approach for predicting off-site odor impacts from odor sources. In this study, the atmospheric dispersion model used is AERMOD which is a model developed by the American Meteorology Society and the U.S. Environmental Protection Agency (EPA) for regulatory purposes, this model was formally proposed by EPA in April 2000 as a replacement for the ISCST3 model. AERMOD is a steady-state advanced plume model that incorporates air dispersion based on planetary boundary layer turbulence structure and scaling concepts, including treatment of both surface and elevated sources and both simple and complex terrain.

It assumes the concentration distribution to be Gaussian in both the vertical and horizontal. In the convective boundary layer, the horizontal distribution is also assumed to be Gaussian, but the vertical distribution is described with a bi-Gaussian probability density function used to calculate the concentrations of gaseous compounds, odors or particulates resulting emission point sources, surface or volume in urban or rural [13].

AERMOD uses hourly weather data as files that contain information about air temperature, wind direction and speed, thermal inversion heights, sunshine (or cloud) and type (urban or rural). Surface parameters required modeling domain (albedo, Bowen 
ratio, roughness) are also included in the model [13].

The model also allows the creation of profiles of temperature, wind and turbulence to determine a height of mechanical and convective mixing. It also incorporates the BPIPPRIME module (Building Profile Input Program) to reflect the wake effect (turbulence) induced by the presence of buildings. Modelling system consists of two pre-processors, namely the meteorological preprocessor (AERMET) and the mapping program (AERMAP) and the dispersion model itself [13].

AERMOD simulates five different plume types depending on the atmospheric stability and on the location in and above the boundary layer: direct, indirect, penetrated, injected, and stable. During stable conditions, plume is modeled with the familiar horizontal and vertical Gaussian formulations. During convective conditions, the horizontal distribution is still Gaussian, the vertical concentration distribution results from a combination of three plume types; the direct plume material, the indirect plume material and the penetrates plume material.

In AERMOD, the total concentration in the convective boundary layer (CBL) is obtained by summing the contribution from the three sources. For the horizontal plume state, the total concentration, $C_{\mathcal{c}}$ is given as:

$$
C_{c}\left(x_{r}, y_{r}, z_{r}\right)=C_{d}\left(x_{r}, y_{r}, z_{r}\right)+C_{r}\left(x_{r}, y_{r}, z_{r}\right)+C_{p}\left(x_{r}, y_{r}, z_{r}\right)
$$

where $C_{d} C_{r}$ and $C_{p}$ are the contributions from the direct, indirect, and penetrated sources, respectively.

Direct source contribution to concentration in the CBL:

$C_{d}\left(x_{r}, y_{r}, z\right)=\frac{Q f_{p}}{\sqrt{2 \pi} u} P_{y} \sum_{j=1}^{2} \sum_{m=0}^{\infty} \frac{\lambda_{j}}{\sigma_{z j}}\left[\exp \left(-\frac{\left(z-\psi_{d j}-2 m z_{j}\right)^{2}}{2 \sigma_{z j}^{2}}\right)+\exp \left(-\frac{\left(z+\psi_{d j}+2 m z_{j}\right)^{2}}{2 \sigma_{z j}^{2}}\right)\right]$

where $f_{p}$ is the fraction of the plume mass trapped in the CBL, $u$ is the wind speed at stack top,

$P_{y}$ is the lateral distribution function, $\psi_{d j}$ and $\sigma_{z j}$ are the effective source height and vertical dispersion parameter corresponding to each of the two vertical velocity distributions.

$$
P_{y}=\frac{1}{\sqrt{2 \pi} \sigma_{y}} e p x\left(-\frac{y^{2}}{2 \sigma_{y}^{2}}\right) \psi_{d j}=h_{s}+\Delta h_{d}+\frac{\bar{w}_{j} x}{u}
$$

Indirect source contribution to concentration in the CBL:

$C_{r}\left(x_{r}, y_{r}, z\right)=\frac{Q f_{p}}{\sqrt{2 \pi} u} P_{y} \sum_{j=1}^{2} \sum_{m=1}^{\infty} \frac{\lambda_{j}}{\sigma_{z j}}\left[\exp \left(-\frac{\left(z+\psi_{r j}-2 m z_{i}\right)^{2}}{2 \sigma_{z j}^{2}}\right)+\exp \left(-\frac{\left(z-\psi_{r j}+2 m z_{i}\right)^{2}}{2 \sigma_{z j}^{2}}\right)\right]$

where $z$ is equal to either $Z_{r}$ for the horizontal plume state or $z_{p}$ for the terrain-following state.

Penetrated source contribution to concentration in the CBL: 
$C_{p}\left(x_{r}, y_{r}, z\right)=\frac{Q\left(1-f_{p}\right)}{\sqrt{2 \pi} u \sigma_{z p}} P_{y} \sum_{m=-\infty}^{\infty}\left[\exp \left(-\frac{\left(z-h_{e p}+2 m z_{i e f f}\right)^{2}}{2 \sigma_{z p}^{2}}\right)+\exp \left(-\frac{\left(z+h_{e p}-2 m z_{\text {ieff }}\right)^{2}}{2 \sigma_{z p}^{2}}\right)\right]$

where $z_{\text {ieff }}$ is the height of the upper reflecting surface in a stable layer and $z$ is equal to either $z_{r}$ for the horizontal plume state or $z_{p}$ for the terrain-following state.

Concentration in the Stable Boundary Layer (SBL):

$C_{s}\left(x_{r}, y_{r}, z\right)=\frac{Q}{\sqrt{2 \pi} u \sigma_{z s}} F_{y} \sum_{m=-\infty}^{\infty}\left[\exp \left(-\frac{\left(z-h_{e s}-2 m z_{i e f f}\right)^{2}}{2 \sigma_{z s}^{2}}\right)+\exp \left(-\frac{\left(z+h_{e s}+2 m z_{i e f f}\right)^{2}}{2 \sigma_{z s}^{2}}\right)\right]$

where $z_{i e f f}$ is the effective mechanical mixer layer height, $\sigma_{z s}$ is the total vertical dispersion in SBL, and $h_{e s}$ is the plume height [13].

Modeling the dispersion of odors is based on hourly meteorological data to estimate the concentrations of odors in the air at various points. In the case of this study, meteorological data for a one-year period (2013) were obtained from an integrated small station in the system located in the study area, a position as to be representative of the wind conditions of the considered emission sources.

Odour perception is proportional to the instantaneous peak concentration of the odorant rather than to mean values. Similarly to other dispersion models, AERMOD is set for calculation of the hourly mean odour. The sensation of odour depends on the momentary (peak) odour concentration and not on a mean value. The peak-to-mean ratio approach has been widely used as solution of this task, in order to be able to calculate the peak values which might occur rather than the hourly mean values.

The equation used to convert the modeled odour concentrations (one hour mean) to peak concentrations is $C_{p}=C_{m}\left(t_{p} / t_{m}\right)^{u}$ using a peak-to-mean factor $\left(t_{p} / t_{m}\right)^{u}$, where $C_{p}$ stands for peak concentration calculated for a short period $t_{p}$ and $C_{m}$ stands for the mean concentration calculated from the dispersion model for a longer period $t_{m}$. Researchers have found values for the power law exponent $(u)$ ranging from -1 to 0 depending on atmospheric stability and also on source to receptor distance, with -0.2 being recommended by most authors. It is assumed that this peak concentration $C_{p}$ is more appropriate to describe the odour sensation of the human nose than the one-hour mean value. This is a way to adopt dispersion models to short-term odor concentrations. The goal of the use of peak-to-mean factors is to mimic the perception of the human nose in a better way as it can be achieved by long term mean values [5].

\subsection{Odor Regulations Used}

The human perception of smells and the annoyance that can derive is the key factor in odour emission control, monitoring and regulation [3].

In order to preserve air quality, many countries and regions throughout the world have been introduce specific legislation on odour, these odor laws are improved gradually and there is no similarity among theme due to cultural, educational and other factors that interfere in the perception of malodours [14]. Currently, in several countries at Europe, North America and Asia, stricter and stricter legislative regulations are being 
adopted, which contain recommendations regarding levels of odour emissions from various sources.

International legislations offer a variety of different regulatory approaches to regulating odours in the ambient air, while the most common approach in these jurisdictions throughout the world is to use guidelines based on odour concentrations. The magnitude of the specific odour concentration limit is highly variable between jurisdictions and depends on factors such as the nature of the impacted region, the averaging time over which the odour concentration is measured, the nature of the source of the odour and the frequency for which compliance is required [3].

The management criterion to prevent the nuisance caused by odour is one of the fundamentals points for regulations and guidelines created in several countries, the existing standards have varying criteria such as odour concentration, substance concentration, minimum distance, duration and Frequency, odour intensity, odour index, nuisance prevention, quantitative emission and complaints best technology.

According to the basic physical, parameter that relates the sense of smell to the odorous substance is concentration, which is expressed as the amount of odorous substances in a volume of air, given in mass fractions (parts per million i.e. ppm) or volume (micrograms per cubic meter i.e. $\mathrm{mg} / \mathrm{m}^{3}$ ).

In many countries, odour impact criteria (OIC) are adopted to determine separation distances between odour sources and residential areas in order to safeguard against nuisance and complaints. There is a wide variety of OIC used for this purpose, which differ by the odour concentration threshold (between 0.12 o.u. ${ }_{\mathrm{E}} / \mathrm{m}^{3}$ and 10 o.u. ${ }_{\mathrm{E}} / \mathrm{m}^{3}$ ), the averaging period (hourly or instantaneous) and by the tolerated exceedance probability of the adopted threshold (between $0.1 \%$ and about $35 \%$ of the time). The calculation of the separation distance is carried out using a dispersion model, which predicts the ambient odour concentration on an hourly basis. This time-series of concentration values allows a calculation of the \% of time in the year during which the threshold odour concentration (OIC) would be exceeded. This can be compared to the tolerated exceedence probability [15].

As Morocco does not still have a specific odour regulation, the odor assessment was performed according to the French regulations for odor emissions based on odor values in the environment, and specifically the Decree of 22 April 2008 that concerns composting facilities submitted to authorization (production capacity above 10 tons/days), with limit for odor concentrations calculated in the environment shall not be higher than 5 u.o. $\mathrm{E} / \mathrm{m}^{3}$ for more than $2 \%$ of the hours in the year ( 175 hours) within a $3000 \mathrm{~m}$ redius from the enclosed limits of the facility.

\subsection{Evaluation Method for Odor Impact}

To allow an impact assessment, the following guideline values are used as context of discussion about exposure to odours:

$\checkmark \quad 1$ o.u. $\cdot \mathrm{m}^{-3}$ point of detection (the level at which an odour is detectable by $50 \%$ of screened panellists). 
$\checkmark \quad 3$ to $5 \mathrm{o.u} \cdot \mathrm{E}_{\mathrm{E}} \cdot \mathrm{m}^{-3}$ the odour recognition threshold, at this concentration, odor is liable to cause offence.

$\checkmark 5$ o.u. $\cdot \mathrm{m}^{-3}$ faint odor, at this concentration, people become consciously aware of the presence of an odor.

$\checkmark 5$ to $10 \mathrm{ou}_{\mathrm{E}} \cdot \mathrm{m}^{-3}$ odors are strong enough to evoke registered complaints.

$\checkmark \quad 10$ o.u. $\cdot \mathrm{m}^{-3}$ distinct odour.

Some authors reported a proposed odour annoyance criterion of 5 or 10 odour units as a 98th percentile, which mean that the level of 5 or 10 o.u. $_{\mathrm{E}} / \mathrm{m}^{3}$ can be exceeded for no more than $2 \%$ of the time[16].

A shade on the last threshold should be introduced, because the complaints also depend on odor intensity, their aggressiveness, their appreciation and finally frequency. It is important to note that the first three parameters are essentially subjective (individual having its own assessment of odor). Thus, some individuals are particularly sensitive and hampered by low concentrations of odors (see below the theoretical threshold of 1 o.u. $\cdot \mathrm{m}^{-3}$ ), while others feel no discomfort at levels above 10 o.u. $\cdot \mathrm{m}^{-3}$. The odor concentration is representative of the average population.

As a guide, it is important to mention that in most countries where there is legislation on odors, the threshold usually used as the acceptable upper limit of ambient air odor concentration is $5 \mathrm{o} \cdot \mathrm{u}_{\mathrm{E}} \cdot \mathrm{m}^{-3}$.

\section{Results and Discussion}

\subsection{Olfactometric Analysis Results}

The first step for assessing the odor impact was to identify odor sources present on the site. Thus, tow main odor sources were identified; the dump fish waste and the hall of fish sale. A sampling campaign was performed to characterize them.

Samples of odor emissions collected in Tedlar bags through dynamic flux chamber (Odoflux) were characterized by dynamic olfactometry in accordance with standard EN 13,725:2003. Analyses were carried out in the Odotech laboratory with odile olfactometer. All the measurements were conducted within $30 \mathrm{~h}$ after sampling, relying on a panel composed of 6 panellists, the panellists were selected based on their individual threshold towards a reference gas (n-butanol in nitrogen) and on the standard deviation of their responses, in conformity with the requirements of the European Standard for dynamic olfactometry, In general, in order to characterize an odour emission, it is necessary to determine the odour emission rate (OER) associated with each odour source, which is measured in $\mathrm{ou}_{\mathrm{E}} \cdot \mathrm{s}^{-1}$ [17] [18].

This sensorial technique is the official method used to determine the concentration, intensity and quality of the odour. Odor concentrations of gas samples is measured in terms of European odour units per cubic metre $\left(\mathrm{ou}_{\mathrm{E}} / \mathrm{m}^{3}\right)$, which represents the number of dilutions with neutral air required to bring an odorous sample to its olfactory threshold concentration [19]. The following table shows the results of this analysis.

As can be seen in the results of the odour quantification in the different samples taken at the sources in fishing port, the geometric mean of the odour concentrations 
(o.u. $/ \mathrm{m}^{3}$ ) and the odour flow (o.u. ${ }_{\mathrm{E}} / \mathrm{h}$ ) was calculated based on the air flow rate $\left(\mathrm{m}^{3} / \mathrm{s}\right)$ feeding dynamic flux chamber. It should be noted that the study area was subject to the peak of odour emission rate $(1,101,597$ u.o.E $/ \mathrm{s})$ generated in fishing port sources, the detail can be seen in Table 1 .

Table 1. The results of the olfactometric analyses.

\begin{tabular}{cccc}
\hline \multirow{2}{*}{ Sources } & Odor Concentration & Odor flow & Contribution of sources \\
\cline { 2 - 4 } & {$\left[\right.$ u.o.E $\left./ \mathrm{m}^{3}\right]$} & {$[$ u.o.E $/ \mathrm{s}]$} & $\%$ \\
\hline Dump fish waste & 1200 & 285,600 & $26 \%$ \\
Hall of fish sale & 1220 & 815,997 & $74 \%$ \\
& Total & $1,101,597$ & \\
\hline
\end{tabular}

\subsection{Simulation of Odour Dispersion}

Atmospheric odor dispersion was modeled on a receptor grid covering an area of 15 $\mathrm{km}$ by $15 \mathrm{~km}$. To represent districts, hotels and public buildings, individual receivers (also called sensitive receptors) were added to the grid of receivers (11). Their localization is shown in the following figures.

This paper focuses on the estimation of peak concentration fluctuations (Figure 2)

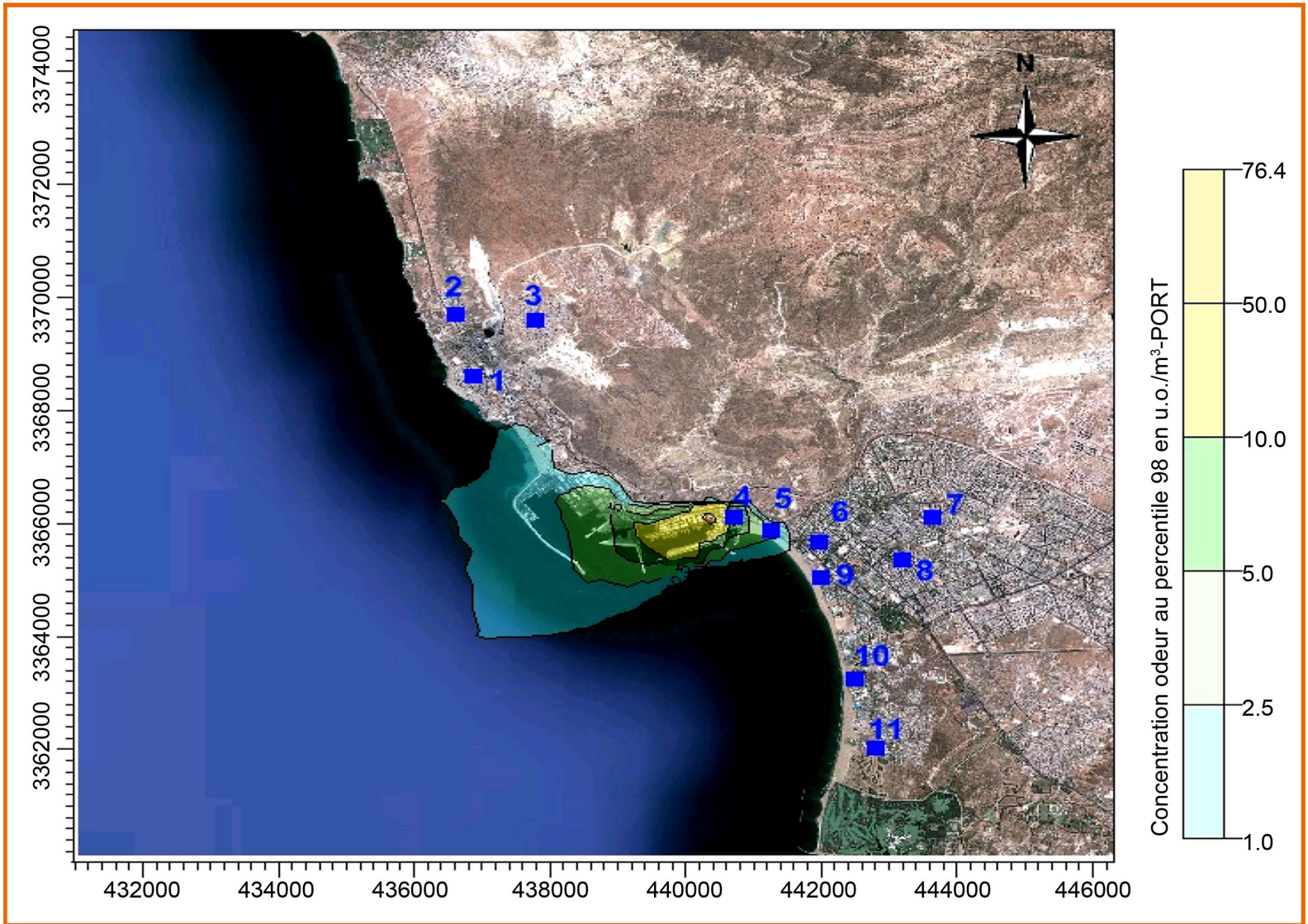

Figure 2. The hourly peak odour concentration values. 
by taking the mean concentrations (Figure 3) and its variance, and using them in a concentration calculation to determine the value that is exceeded some specified fraction of the time (Figures 4-6).

Figures 3-6 show the results of the simulation of the odour emission dispersion.

As shown in Table 2, in the tourist area (R4, R5, R6, R9, R10 and R11), standards values are exceeded according to the Decree of 22 April 2008, the maximum odor concentrations vary from 5 u.o. ${ }_{\mathrm{E}} / \mathrm{m}^{3}$ to $30 \mathrm{u}$.o. ${ }_{\mathrm{E}} / \mathrm{m}^{3}$, which is a very strong impact compared to other sites.

At the receptor $\mathrm{R} 4$ and receptor $\mathrm{R} 9$, the odors from the fishing port are likely to be perceived (the $1 \mathrm{uo}_{\mathrm{E}} / \mathrm{m}^{3}$ ) respectively $15 \%$ of the time (55 days/year) and $4 \%$ of the time (14.6 days/year) as shown in Figure 5. In the case of recognition threshold $\left(5\right.$ u.o.E.E $\left./ \mathrm{m}^{3}\right)$, the excedeence frequency for the receptor R4 and receptor R5 is respectively 6\% (30 days/year) and 1\% (3.6 days/year) as shown in Figure 6.

Thus, it is evident that the fishing port has a major odor impact on the tourist area and the downtown. This is mainly due to its geographical proximity to these impact zones and the weather conditions. Indeed, besides emissions (odors rates), atmospheric stability conditions have a significant impact on odors generated.

The stability of the atmosphere can be expressed in terms of the Pasquill classes A-G, where A is strongly unstable, D is neutral, and G is strongly stable [20] [21]. Alternatively, the stability can be expressed by the Monin-Obukhov length, denoted by LMO.

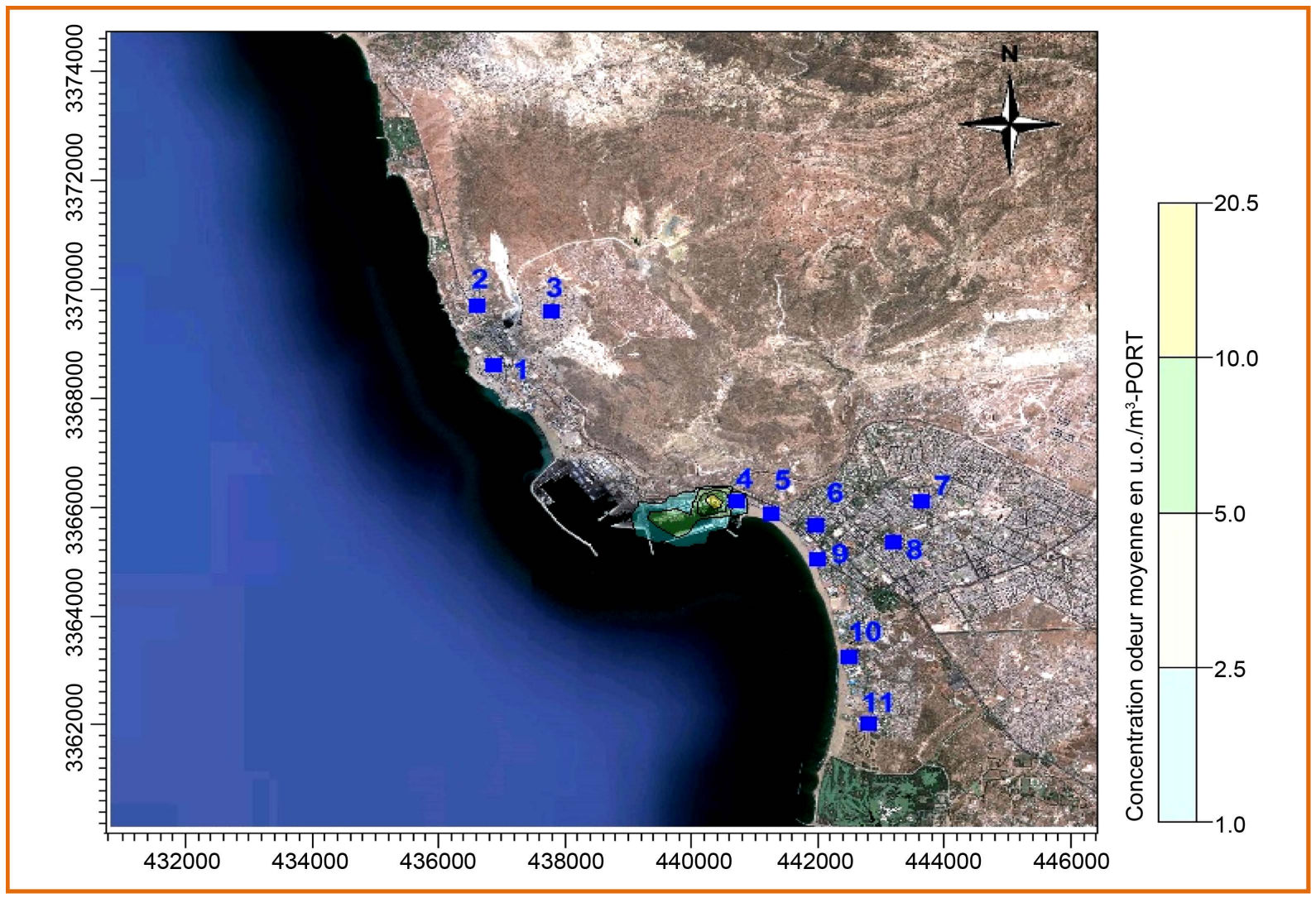

Figure 3. Hourly mean odor concentration. 


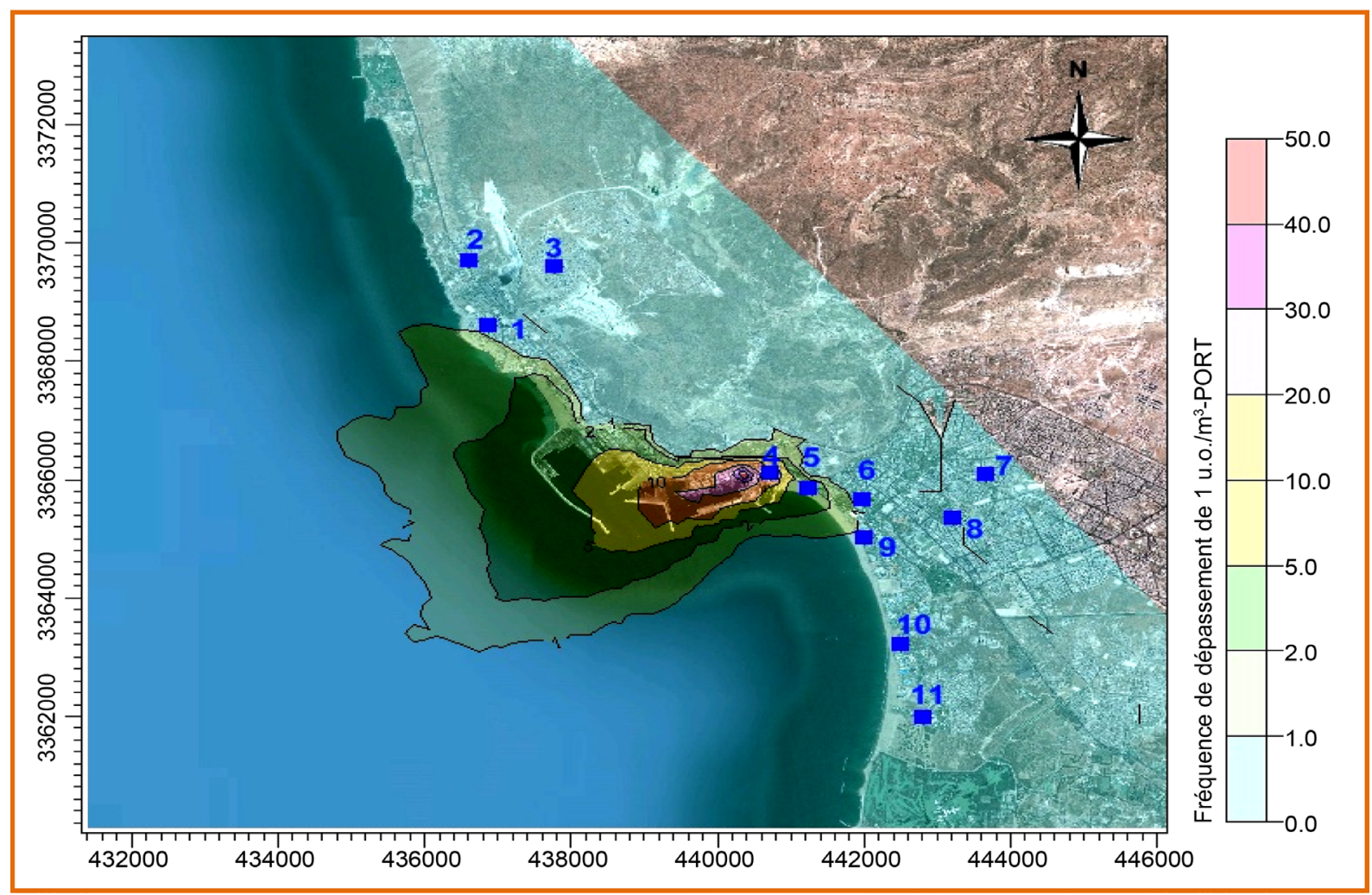

Figure 4. The 98th percentile of the hourly peak odour values.

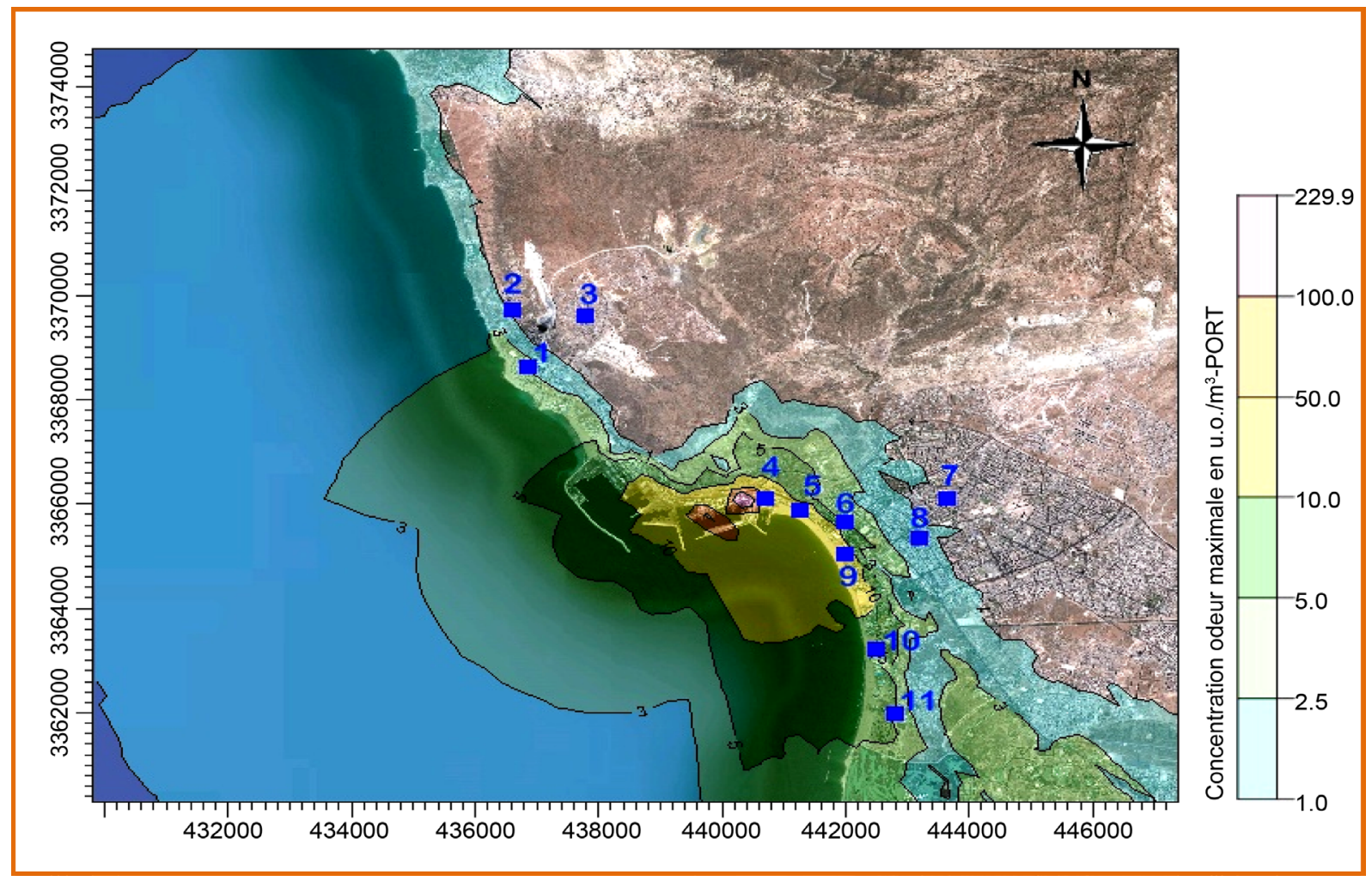

Figure 5. 1 u.o. ${ }_{\mathrm{E}} / \mathrm{m}^{3}$ threshold exceedance frequency. 


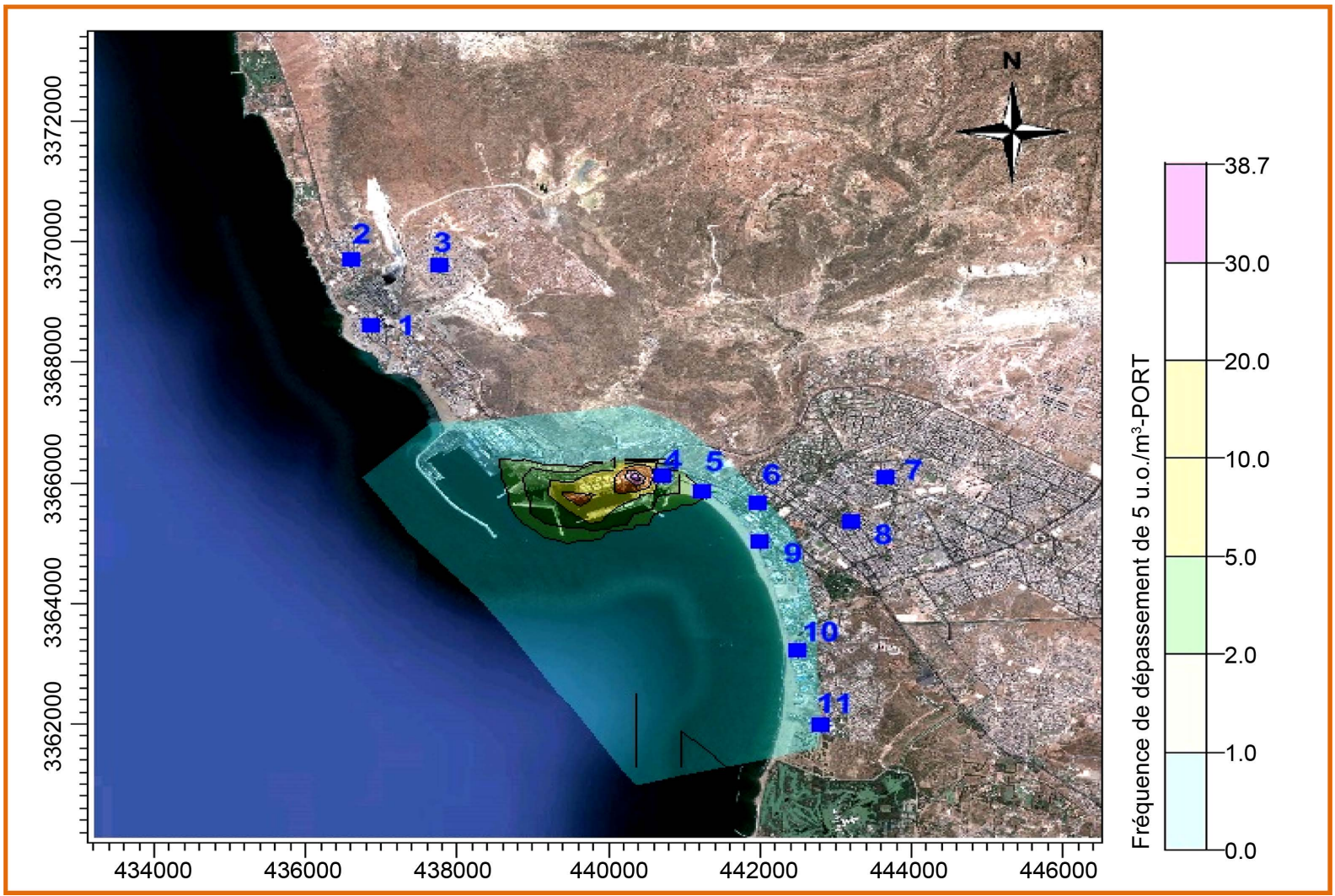

Figure 6. 5 u.o. $\mathrm{E} / \mathrm{m}^{3}$ threshold exceedance frequency.

Table 2. Overview of modeled odors impacts in selected receptors.

\begin{tabular}{cccccc}
\hline \multirow{2}{*}{ Receptor } & \multicolumn{3}{c}{ Odor Concentration } & \multicolumn{2}{c}{ Exceeded Thresholds } \\
\cline { 2 - 6 } & 1st Max & Medium & 98 th Percentile & 1 u.o.E $/ \mathrm{m}^{3}$ & $5 \mathrm{u} . \mathrm{O}_{\mathrm{E}} / \mathrm{m}^{3}$ \\
\cline { 2 - 6 } & u.o.E $/ \mathrm{m}^{3}$ & u.o.E $/ \mathrm{m}^{3}$ & u.o.E $/ \mathrm{m}^{3}$ & $\%$ & $\%$ \\
\hline 1 & 3 & $<1$ & 0.2 & $1 \%$ & $0.0 \%$ \\
2 & $<1$ & $<1$ & $<1$ & $0.0 \%$ & $0.0 \%$ \\
3 & $<1$ & $<1$ & $<1$ & $0.0 \%$ & $0.0 \%$ \\
4 & 30 & 2 & 14 & $15 \%$ & $6 \%$ \\
5 & 23 & $<1$ & 3 & $4 \%$ & $1.0 \%$ \\
6 & 5 & $<1$ & $<1$ & $1 \%$ & $0.0 \%$ \\
7 & $<1$ & $<1$ & $<1$ & $<0.1 \%$ & $<0.1 \%$ \\
8 & 1,1 & $<1$ & $<1$ & $<0.1 \%$ & $<0.1 \%$ \\
9 & 15 & $<1$ & $<1$ & $1 \%$ & $0.2 \%$ \\
10 & 8 & $<1$ & $<1$ & $0.2 \%$ & $<0.1 \%$ \\
11 & 6 & $<1$ & $<1$ & $0.1 \%$ & $<0.1 \%$ \\
\hline
\end{tabular}

Atmospheric stability conditions are unstable, neutral, and stable, when 1/LMO is negative, zero, and positive, respectively [22] [23]. 
Strongly unstable weather occurs during hot, sunny days when rapid vertical mixing occurs, neutral atmospheric conditions may occur at any time of the day under high wind speed and/or over cast sky, strongly stable atmospheric conditions occur during calm, clear nights when vertical mixing is nearly non-existent. These conditions strongly influence the dispersion of odours [24]. Unstable conditions facilitate the vertical dispersion of odours while stable conditions help odours travel horizontally [25].

Several studies have been conducted to identify and characterize relationships between meteorological conditions and impaired air quality episodes. Dispersion models have become a common tool to evaluate the impacts of odour sources for given meteorological [26] [27] [28].

Over this study we note that wind direction determined the odour dispersion direction and length. The shape of the odour plume followed wind direction as showed in Figure 7.

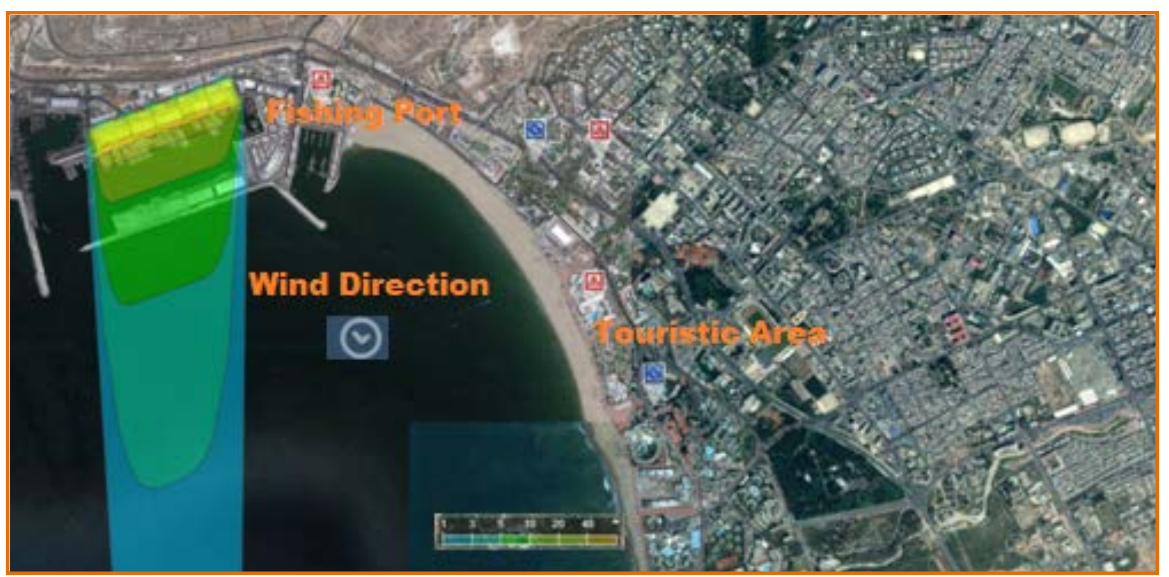

Figure 7. Maps of odour concentrations simulated using Aermod.

Generally, atmospheric stability condition was found to have a major impact on odor plume length because it established the wind velocity range and the temperature gradient as well as the strength of the convective air forces, wind direction had an impact on the direction and length of the odour plume. Neutral atmospheric stability conditions produced as horter odour plume length compared with unstable and stable conditions because of stronger convective effects [29].

\subsection{Mobile E-Nose Analyses}

The mobile e-nose is housed in mobile laboratory with temperature controlled and dust-free condition. The mobile air quality laboratory was deployed to the sampling site (R6) and was operated over one year (2013) for the continuous air pollution monitoring work. The e-nose is calibrated to measure odors in ambient air and every four minutes a measurement is carried out. During assessed period, 79,735 odor concentration measurements were recorded with values between 1 u.o. ${ }_{\mathrm{E}} / \mathrm{m}^{3}$ and 9 u.o. ${ }_{\mathrm{E}} / \mathrm{m}^{3}$.

The following figure show the typical profiles of daily odor evolution for a representative day for most of the time. 
Odor concentrations vary according to the activities in the emission sources and the weather conditions, generally during this period, there were on average lower concentrations, even in the afternoon, when production start in fishing facilities in the industrial area of Anza. There is also a decrease toward $13 \mathrm{~h}$ and when there is no activity on the site, the concentrations are very low as shown in Figure 8.

At night time, drainage winds originating on the slopes of the neighbouring mountains dispersed the fishing port plume towards the city. Later in the day, the penetration of the sea breeze and the formation of up slope winds, together with the deepening of the mixing layer, moved the plume towards the south east of the domain and diluted concentrations.

The distribution of odor concentrations indicate that concentrations between 1 and 5 u.o. ${ }_{\mathrm{E}} / \mathrm{m}^{3}$ are the frequent values that represent $97 \%$ of the values measured as shown in Figure 9. The thresholds 5 u.o.E $/ \mathrm{m}^{3}$ was exceeded 1347 times all the in December, this

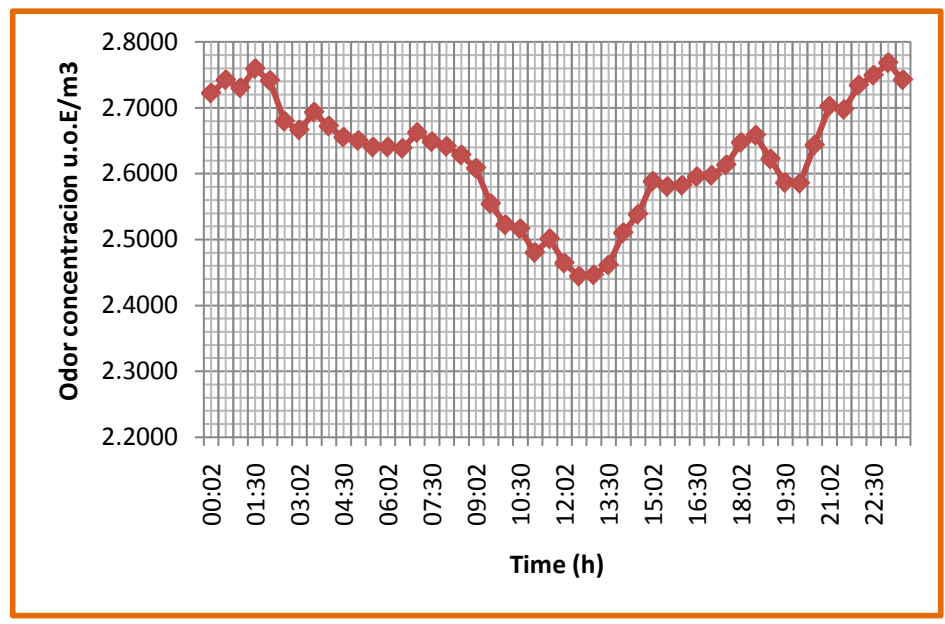

Figure 8. Odor concentration distribution on the specific day $(10 / 1 / 2013)$ measured by the e-nose at R9.

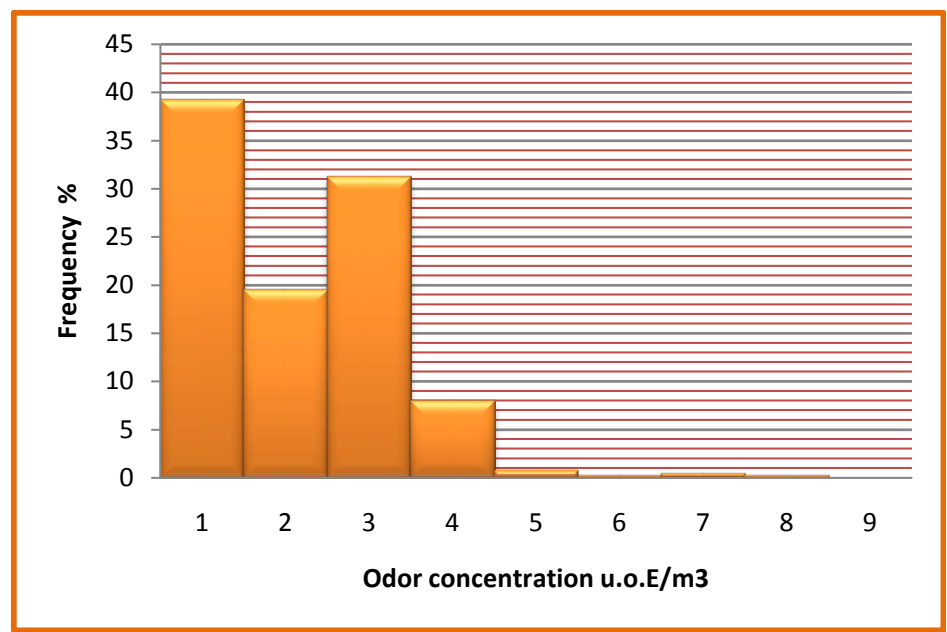

Figure 9. Distribution of odor concentrations measured by the e-nose at R9 during 2013. 
threshold represent less than $1.69 \%$ of odor concentrations measured in this period.

The maximum value measured by the e-nose is 8.5 u.o. ${ }_{\mathrm{E}} / \mathrm{m}^{3}$ (30 December 2013, at $7: 44)$ and the average value measured is 2.47 u.o. ${ }_{\mathrm{E}} / \mathrm{m}^{3}$.

We have analyzed e-nose measurement in comparison with the meteorological data which are obtained from a mobile laboratory located in the study area (R9) during the assessment period (2013). The wind rose calculated over this year is shown in Figure below.

The wind rose diagram for half-hourly averaged wind speed over the entire sampling duration (2013) is presented in Figure 10. The wind directions cover different wind angles, these wind directions were northwest $(\mathrm{NW})$, north $(\mathrm{N})$, northeast $(\mathrm{NE})$, east $(\mathrm{E})$, southeast (SE), south (S), southwest (SW) and west (W).

The frequencies of winds from NW, SE, NE, SW, E and W were $3.5 \%, 3.5 \%, 4.4 \%$, $12 \%, 11 \%$ and $9 \%$ respectively, indicating that only a small data set was available for NW, SE, and NE, and no data was obtained for S and N winds (Figure 10).

The prevailing winds are mainly from the West, South-West and East. The wind class frequency distributions indicate that the most unfavorable wind conditions on odor dispersion are more than $38 \%$.

The direction of wind reveals that a minority of them is likely to cause odor transport from the fishing port to the tourist area and to downtown (from the northwest to the southeast). On the other hand, the presence of the cornice and mountain is likely to

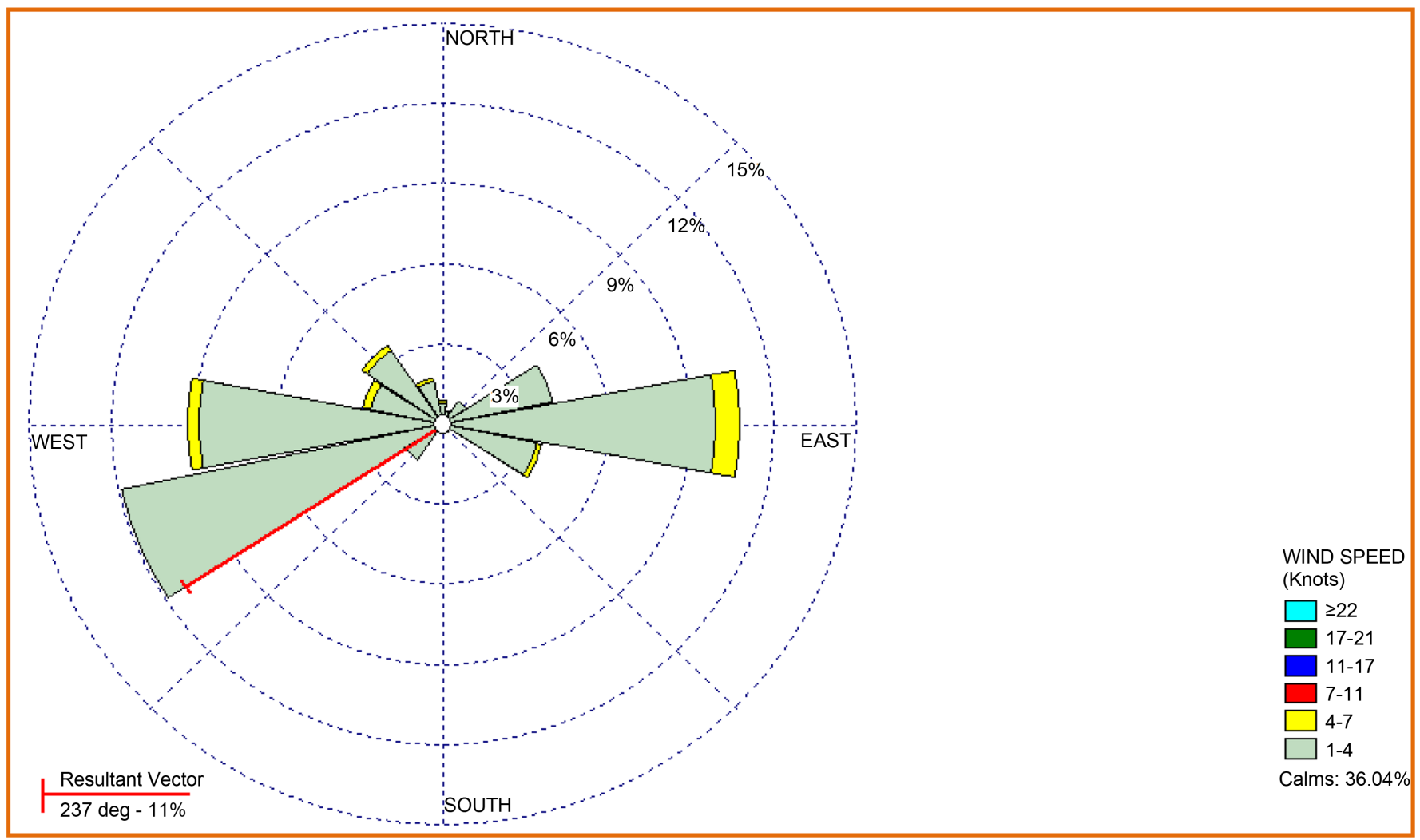

Figure 10. Area study wind rose in 2013. 
create a preferential passage to the tourist area and to downtown by passing winds from West-South-West and South [10].

Through e-nose measurement associated with meteorology data, it appears that odor peaks are associated with weather conditions, thus the peaks odor concentrations occur when the winds are very low, less than $2 \mathrm{~m} / \mathrm{s}$, and more the wind is lower more the probability to have odor episode is important, so that the strong wind disperses the odors more quickly, the figure bellow illustrate the localization of the emission sources and the receptor R9 which are aligned with direction in December 2013.

During 2013, only in December that the wind rose for receptor R6 (Wilaya) showed a prevalence of north westerly winds in this receptor. It was found that a fishing port is aligned with this wind direction as shown in Figure 11, these events associated with stagnant weather conditions with limited vertical mixing and low wind speeds are the substantiation of odor concentrations peaks measured at R6 during assessment period using e-nose and the results of the simulation of the odour emission dispersion. For these reason, the odor concentrations peaks measured at R6 during assessment period using e-nose occurred only in December 2013.

The results in the receptor R6 at the assessment period (2013) show a good agreement between the model simulation and the mobile e-nose. The results obtained from each method were confirmed to each other, which led to a conclusion on the origin of episodes in the designated receptor. In comparison with olfactometry assessment considered a costly method due to the cost of sample collection and analysis, these tow techniques present other advantages like the rapidity, the lower costs, the repeatability of the results and the continuous monitoring.

In this project, the model simulation is used to predict olfactory nuisances that lead to the majority of complaints in neighbourhoods surrounding the fishing port and to identify the most affected areas of the city by odor emissions and to recognize the meteorological parameters maximizing odor impact, but modeling does not take into account fugitive emissions reliably in the absence of data on these emissions, modeling based on the hourly average misjudges the odor peaks. The e-nose is used to monitor ambient odor emissions in real time and made it possible to obtain validated data and

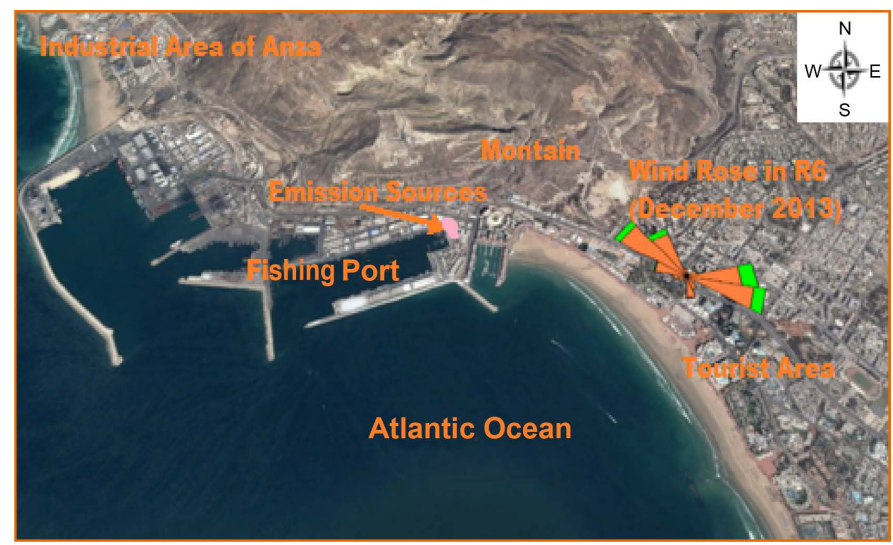

Figure 11. Localization of the emission sources and the receptor R9. 
provides accurate, affordable and real-time odour measurement capability tacking in to account the role of human perception without being able to characterize the extent of the odor nuisance caused by each source. The comparison between tow methodologies based on the frequency of odor episodes high-lighted that the model tended to underestimate peak intensities while the appropriate peak-to-mean factor is difficult to choice.

The results obtained emphasize the advantages of assessment the odor impact with these three approaches. Each approach gives different information about the emissions and odour impact around fishing port, the coordination of the three approaches permits optimization of the advantages offered by both methods to the measurable and objective evaluation of the odour nuisance.

In order to maintain the quality of the environment in Agadir city, efforts to abate odor levels are necessary, in this sense the odour management plan (OMP) must be developed to provide guidance to on-site Agadir city management authority, this OMP well outlines the methods by which this authority will systematically assess, reduce and prevent potentially odorous

\section{Conclusions}

In this study the methodology adopted to assess odor impact around Agadir fishing port is described which is based on three methods such as dynamic olfactometry, dispersion modeling and mobile e-nose. These three valuation methods provide complementary information about odor nuisance. The olfactometric measurements allowed to determine the peak of odour emission rate $(1,101,597$ u.o.E/s) generated in fishing port sources. The evaluation of odor impact on the study area with model dispersion enabled to identify the most affected areas of the city and to underline the key role of local atmospheric dynamics in driving the dispersion of odours.

The comparison between the results of the odour dispersion modeling and e-nose measurements based on the frequency of odor episodes high-lighted that the model tended to underestimate peak intensities while the appropriate peak-to-mean factor is difficult to choice. In general the two techniques were in good agreement in terms of the assessment of the spatial extent of odor nuisance and provide reasonable results.

The relation between the results of the dispersion modeling with those obtained with the electronic nose appears to be an interesting research area and there are opportunity to improve the precision of the two methods and harmonize them, and highlight different strengths and weaknesses in both approaches.

\section{Acknowledgements}

The authors would like to greatly thank the Wali and the President of the Souss Massa Region for their support to this Work.

\section{References}

[1] Gallego, E., Soriano, C., Roca, F.X., Perales, J.F., Alarcon, M. and Guardino, X. (2008) Identification of the Origin of Odour Episodes through Social Participation, Chemical Control 
and Numerical Modeling. Atmospheric Environment, 42, 8150-8160.

http://dx.doi.org/10.1016/j.atmosenv.2008.08.004

[2] Capelli, L., Sironi, S., Del Rossoa, R., Céntola, P., Rossi, A. and Austeri, C. (2011) Odour Impact Assessment in Urban Areas: Case Study of the City of Terni. Procedia Environmental Sciences, 4, 151-157. http://dx.doi.org/10.1016/j.proenv.2011.03.018

[3] Nicell, J.A. (2009) Assessment and Regulation of Odour Impacts. Atmospheric Environment, 43, 196-206. http://dx.doi.org/10.1016/j.atmosenv.2008.09.033

[4] Freeman, T. and Cudmore, R. (2002) Review of Odour Management in New Zealand. Air Quality Technical Report No. 24, New Zealand Ministry of Environment, Wellington.

[5] Schauberger, G. and Piringer, M. (2012) Assessment of Separation Distances to Avoid Odour Annoyance: Interaction between Odour Impact Criteria and Peak-to-Mean Factors. Chemical Engineering Transactions, 30, 13-18

[6] Ranzato, L., Barausse, A., Mantovani, A., Pittarello, A., Benzo, M. and Palmeri, L. (2012) A Comparison of Methods for the Assessment of Odor Impacts on Air Quality: Field Inspection (VDI3940) and the Air Dispersion Model CALPUFF. Atmospheric Environment, 61, 570-579. http://dx.doi.org/10.1016/j.atmosenv.2012.08.009

[7] Seo, S.-G., Ma, Z.-K., Jeon, J.-M., Jung, S.-C. and Lee, W.-B. (2011) Measurements of Key Offensive Odorants in a fishery Industrial Complex in Korea. Atmospheric Environment, 45, 2929-2936. http://dx.doi.org/10.1016/j.atmosenv.2011.01.032

[8] Capelli, L., Sironi, S. and Del Rosso, R. (2014) Electronic Noses for Environmental Monitoring Applications, Sensors, 14, 19979-20007. http://dx.doi.org/10.3390/s141119979

[9] Romain, A.C. and Nicolas, J. (2010) Long Term Stability of Metal Oxide-Based Gas Sensors for E-Nose Environmental Applications: An Overview. Sensors and Actuators B: Chemical, 146, 502-506. http://dx.doi.org/10.1016/j.snb.2009.12.027

[10] Kermani, B.G., Schiffman, S.S. and Nagle, H.T. (2005) Performance of the LevenbergMarquardt Neural Network Training Method in Electronic Nose Applications. Sensors and Actuators B: Chemical, 110, 13-22. http://dx.doi.org/10.1016/j.snb.2005.01.008

[11] Chirmata, A., Ichou, I.A. and Page, T. (2015) A Continuous Electronic Nose Odor Monitoring System in the City of Agadir Morocco. Journal of Environmental Protection, 6, 5463. http://dx.doi.org/10.4236/jep.2015.61007

[12] Brancher, M. and De Melo Lisboa, H. (2014) Odour Impact Assessment by Community Survey. Chemical Engineering Transactions, 40, 139-144.

[13] AERMOD (2004) Description of Model Formulation. Report EPA-454/R-03-004, US Environmental Protection Agency, Research Triangle Park.

[14] Gebicki, J., Byliński, H. and Namieśnik, J. (2016) Measurement Techniques for Assessing the Olfactory Impact of Municipal Sewage Treatment Plants. Environmental Monitoring and Assessment, 188, 32. http://dx.doi.org/10.1007/s10661-015-5024-2

[15] Sommer, E.N., Piringer, M., Petz, E. and Schauberger, G. (2014) National Odour Impact Criteria: Are the Modelled Separation Distances between Sources and Receptors Comparable? Chemical Engineering Transactions, 40, 175-180.

[16] Simms, K.L., Wilkinson, S. and Bethan, S. (1999) Odour Nuisance and Dispersion Modelling: An Objective Approach to a Very Subjective Problem. Proceedings of IAWQ/CIWEM International Conference on the Control and Prevention of Odours in the Water Industry, London, 22-24 September 1999.

[17] CEN (2003) EN 13725 2003: Air Quality-Determination of Odour Concentration by Dynamic Olfactometry. Brussels. 
[18] Capelli, L., Sironi, S., Del Rosso, R., Céntola, P. and Bonati, S. (2010) Improvement of Olfactometric Measurement Accuracy and Repeatability by Optimization of Panel Selection Procedures. Water Science and Technology, 61, 1267-1278.

http://dx.doi.org/10.2166/wst.2010.023

[19] CEN (2007) EN 13725 2003: Air Quality-Determination of Odour Concentration by Dynamic Olfactometry; Comitée Européen de Normalisation. Brussels.

[20] Beychok, M.R. (1994) Fundamentals of Stack Gas Dispersion. 3rd Edition, Milton R. Beychok, Newport Beach.

[21] Schnelle Jr., K.B. and Dey, P.R. (2000) Atmospheric Dispersion Modeling Compliance Guide. Mc Graw Hill Companies, NewYork.

[22] Carruthers, D.J., Holroyd, R.J., Hunt, J.C.R., Weng, W.S., Robins, A.G., Thomson, D.J. and Smith, F.B. (1994) UKADMS, A New Approach to Modelling Dispersion in the Earth's Atmospheric Boundary Layer. Journal of Wind Engineering and Industrial Aerodynamics, 52, 139-153. http://dx.doi.org/10.1016/0167-6105(94)90044-2

[23] Panofsky, H. and Dutton, J. (1984) Atmospheric Turbulence. John Wiley \& Sons, New York, 397 p.

[24] Kumar, P., Fennell, P. and Britter, R. (2008) Effect of Wind Direction and Speed on the Dispersion of Nucleation and Accumulation Mode Particles in an Urban Street Canyon. Science of the Total Environment, 402, 82-94. http://dx.doi.org/10.1016/j.scitotenv.2008.04.032

[25] Guo, H., Feddes, J., Dehod, W., Laguë, C. and Edeogu, I. (2006) Monitoring of Odour Occurrence in the Vicinity of Swine Farms by Resident-Observers Part II: Impact of Weather Conditions on Odour Occurrence. Canadian Biosystems Engineering, 48, 6.23-6.29.

[26] Yang, G. and Hobson, J. (2000) Odour Nuisance Advantages and Disadvantages of a Quantitative Approach. Water Science and Technology, 41, 97-106.

[27] McIntyre, A. (2000) Application of Dispersion Modelling to Odour Assessment: A Practical Tool or a Complex Trap? Water Science and Technology, 41, 81-88.

[28] Stuetz, R. and Frechen, F.-B. (Eds.) (2001) Odours in Waste Water Treatment: Measurement, Modelling and Control. IWA Publishing, London, $456 \mathrm{p}$.

[29] Lin, X.-J., Barrington, S., Choinière, D. and Prasher, S. (2009) Effect of Weather Conditions on Windbreak Odour Dispersion. Journal of Wind Engineering \& Industrial Aerodynamics, 97, 487-496. http://dx.doi.org/10.1016/j.jweia.2009.06.012 
Submit or recommend next manuscript to SCIRP and we will provide best service for you:

Accepting pre-submission inquiries through Email, Facebook, LinkedIn, Twitter, etc. A wide selection of journals (inclusive of 9 subjects, more than 200 journals)

Providing 24-hour high-quality service

User-friendly online submission system

Fair and swift peer-review system

Efficient typesetting and proofreading procedure

Display of the result of downloads and visits, as well as the number of cited articles

Maximum dissemination of your research work

Submit your manuscript at: http://papersubmission.scirp.org/

Or contact jep@scirp.org 